\title{
Intensive care medicine: a specialty coming to LIFE
}

The Lancet today includes three papers about intensive care medicine. The papers describe the evolution of the specialty, ${ }_{1}$ the demand for and ability to supply appropriate levels of care, ${ }^{2}$ and some of the commonly faced ethical dilemmas and challenges. ${ }^{3}$ These topics are apt in this period of economic constraint. Intensive care medicine consumes a considerable proportion of health-care resources ${ }^{4}$ and these costs will need to be justified. The appropriateness and effectiveness of the care provided will need to be improved to ensure that these resources are directed to patients most in need of them. Intensive care medicine is the science and art of preventing, caring for, and when possible curing acutely unwell patients. It is a young specialty, originating from the 1952 Copenhagen poliomyelitis epidemi ${ }^{5,6}$ and the subsequent realisation that multisystem monitoring, support, and reanimation are often required. ${ }^{7.8}$

Jean-Louis Vincent and Mervyn Singer ${ }^{1}$ review the improvements in practice that have been made over the past few decades and extrapolate forward. What is striking is the fact that despite the expenditure of a great amount of time, energy, and resources, the search for a cure-all magic bullet has failed. What has become apparent, however, is the need for a greater understanding of the basic processes involved in the care of sick patients, and how this increased understanding can be used to improve patient outcomes. Intensive care medicine has evolved from being mainly driven by new technologies, often on the basis of the practical application of well-known physiological principles, to a more holistic, proactive, patient-centred approach. In the past, there was a perception that intensive care medicine was about only looking at and mostly reacting to numbers. This approach was unsurprising when past intensive-care units are considered-the machines often outnumbered the patients and hid them behind cloaks of mystique. When new concepts and technologies are introduced into practice, it is all too easy to focus on only the potential benefits. With some techniques, these benefits are obvious; sadly however, with many, these benefits must be weighed against the potential for harm. The balance can be fine and might only become apparent after many years. ${ }^{9}$ We should be open-minded enough to adopt new theories and practices, but not without suitable cynicism so as to not add further risk.
Intensive care medicine is about the combination of high-intensity hands-on care with the rational use of modern technology. Understanding the limitations of what can be done-often for elderly frail patients with multiple comorbidities-is crucially important and needs appropriate numbers of accredited specialists.

Neill Adhikari and colleagues ${ }^{2}$ describe the increased global burden of critical illness and the implications of this increase on staffing structures. The need to attract young trainee doctors to intensive care medicine is obvious. In the USA, attempts to meet the challenge are based on the creation of a new class of physician extenders, nursing practitioners, and telemedicine. Most European countries have taken a different stance by aiming to increase the number of new specialists capable of delivering this care. For this reason, the European Board of Intensive Care Medicine believes that we need to increase the recognition of intensive care medicine within European legislation. Intensive care medicine is not yet described as a specialty, ${ }_{1}^{10}$ which has obvious implications for its profile, ability to attract trainees, and the overall quality of care. Quality of care should be effective, safe, and accessible. We should therefore continue to improve our understanding of how the structures and processes that underpin care pathways influence overall outcomes. For this reason, the European Society of Intensive Care Medicine (ESICM), together with more than 60 other national societies in intensive care medicine, signed the Declaration of

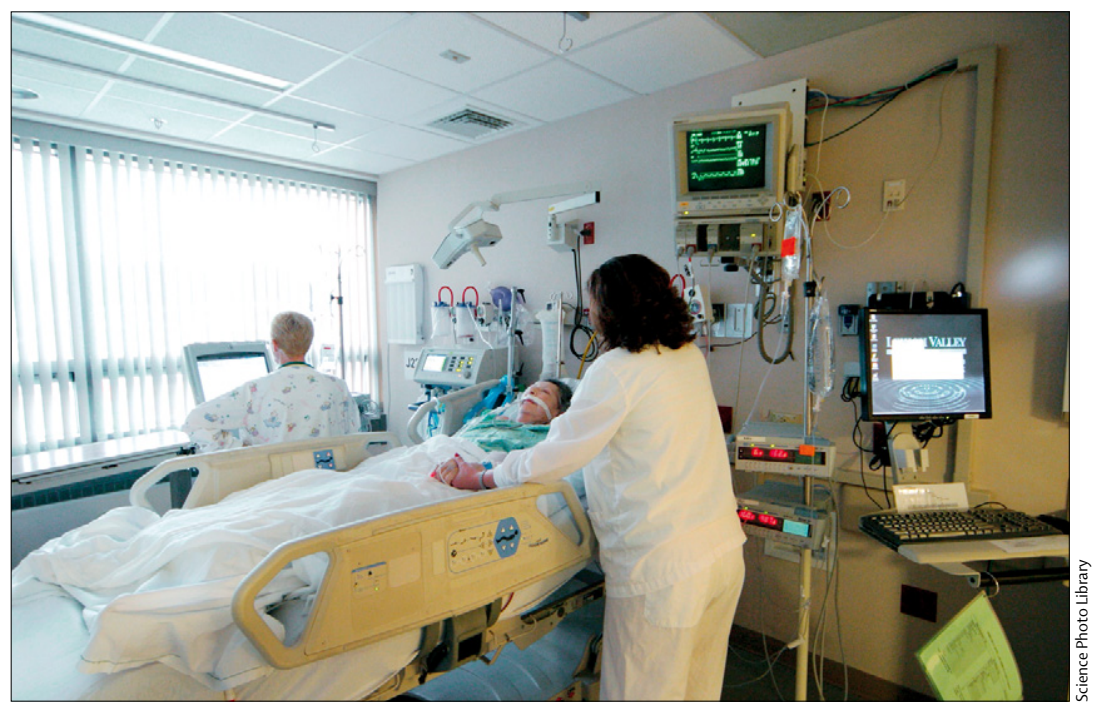

Published Online October 9, 2010 DOI:10.1016/S0140 6736(10)61502-4

See Editorial page 1273

See Series pages 1339,1347 , and 1354 
Vienna, ${ }_{1}^{11}$ openly pledging to direct resources and time towards improving the quality and safety of care for sick patients. However, quality should also be assessed both from the perspectives of health-care professionals and from the patient or their surrogate. This experience of care is the fifth domain of quality from the National Quality Measures Clearinghouse. ${ }^{12}$ In October, 2010, ESICM is therefore launching their Linking Intensive Care to Family Experience (LIFE) campaign in Barcelona. This campaign is an attempt to continue to improve quality, but by including the views of patients and their partners. Only with this domain can we be sure that what we believe is quality is what will really make the difference. As Henry Ford described, "quality is doing it right when no one is looking".

\section{${ }^{*}$ Rui Paulo Moreno, Andrew Rhodes}

Unidade de Cuidados Intensivos Polivalente, Hospital de Santo António dos Capuchos, Centro Hospitalar de Lisboa Central, EPE, Lisbon 1169-050, Portugal (RPM); and St George's Healthcare NHS Trust, General Intensive Care, London, UK (AR) r.moreno@mail.telepac.pt

RPM is the president and AR the president-elect of the European Society of Intensive Care Medicine.
1 Vincent J-L, Singer M. Critical care: advances and future perspectives. Lancet 2010; published online Oct 9. DOI:10.1016/S0140-6736(10)60575-2.

2 Adhikari NKJ, Fowler RA, Bhagwanjee S, Rubenfeld GD. Critical care and the global burden of critical illness in adults. Lancet 2010; published online Oct 9. DOI:10.1016/S0140-6736(10)60446-1.

3 Curtis JR, Vincent J-L. Ethics and end-of-life care for adults in the intensive care unit. Lancet 2010; published online Oct 9. DOI:10.1016/S01406736(10)60143-2.

4 Halpern NA, Pastores SM. Critical care medicine in the United States 2000-2005: an analysis of bed numbers, occupancy rates, payer mix, and costs. Crit Care Med 2010; 38: 65-71.

5 Lassen HC. A preliminary report on the 1952 epidemic of poliomyelitis in Copenhagen with special reference to the treatment of acute respiratory insufficiency. Lancet 1953; 1: 37-41.

6 Ibsen B. The anaesthetist's viewpoint on the treatment of respiratory complications in poliomyelitis during the epidemic in Copenhagen, 1952. Proc R Soc Med 1954; 47: 72-74.

7 Negovsky VA. Some physiopathologic regularities in the process of dying and resuscitation. Circulation 1961; 23: 452-57.

8 Negovsky VA. Essays on reanimatology. Moscow: Mir Publishers, 1986.

9 Kraemer HC, Frank E. Evaluation of comparative treatment trials: assessing clinical benefits and risks for patients, rather than statistical effects on measures. JAMA 2010; 304: 683-84.

10 Official journal of the European Union. Directive 2005/36/EC of the European Parliament and of the council of 7 September 2005 on the recognition of professional qualifications. Sept 30, 2005. http://eur-lex. europa.eu/LexUriServ/LexUriServ.do?uri=0J:L:2005:255:0022:0142:en:PDF (accessed Oct 1, 2010)

11 Moreno RP, Rhodes A, Donchin Y, for the European Society of Intensive Care. Patient safety in intensive care medicine: the Declaration of Vienna. Intensive Care Med 2009; 35: 1667-72.

12 European Society of Intensive Care Medicine. Quality in critical care. In Chiche J-D, Moreno RP, Putensen C, Rhodes A, eds. Patient safety and quality of care in intensive care medicine. Berlin: MWV Medizinisch Wissenschaftliche Verlagsgesellschaft, 2009: 127-41.

\section{@ Kidneys donated after cardiac death are acceptable}

Published Online August 19, 2010 DOI:10.1016/S0140-

6736(10)61078-1

See Articles page 1303
Dominic Summers and colleagues, in The Lancet today, ${ }^{1}$ have carefully analysed the factors that affect outcome after transplantation of kidneys from deceased donors in the UK. Outcomes were for kidneys donated after cardiac death (cessation of cardiac activity) and after brain-stem death. Today's analysis includes more than 9000 recipients of kidney transplants from 2000 to 2007 , during which time $10 \%$ of patients received a kidney from a cardiac-death donor and the remaining patients received kidneys from brain-death donors.

Over the past 2-3years, the use of cardiac-death donors has increased substantially in the UK and almost 30\% of all deceased donor kidneys used in renal transplantation are from cardiac-death donors. ${ }^{2}$ The rising demand for kidneys for transplantation and the decreasing number of brain-death donors has led to the increasing use of cardiac-death donors. Kidneys from cardiac-death donors are regarded as marginal kidneys; there has therefore been concern that their use would lead to an increase in delayed graft function, which would be reflected by impaired renal function and poorer graft survival. Summers and colleagues confined their analysis to Maastricht category 3 donors, namely controlled cardiac-death donors, ${ }^{3}$ which means removal of kidneys after cessation of cardiac activity in the donor following withdrawal of respiratory and circulatory support. It should be remembered that in the 1970 s, before brainstem death was accepted as a diagnosis of death, all kidneys were retrieved after cessation of cardiac activity, mostly in a controlled situation, and were the equivalent of Maastricht 3 donors. Excellent results were obtained with the immunosuppression available at that time, even though delayed graft function occurred in 10-50\% of recipients. ${ }^{4,5}$

In today's analysis, delayed graft function was increased in kidneys from cardiac-death donors (50\%) compared with kidneys from brain-death donors (25\%). Estimated glomerular filtration rate (after adjustment for possible confounding factors) was inferior at 3 months in recipients of kidneys from cardiac-death 